\title{
EDUKASI GAYA KEPEMIMPINAN TRANSFORMASIONAL TERHADAP BUDAYA KERJA BAGI OSIS SMK MUTIARA BANGSA TIGA
}

\author{
Herlina Budiono ${ }^{1}$, Steven $^{2}$, Vanessa Angelica Budiono ${ }^{3}$ dan Yosafat Raymond ${ }^{4}$
}

\author{
${ }^{1}$ Program Studi Manajemen, Universitas Tarumanagara Jakarta \\ Email:herlinab@fe.untar.ac.id \\ ${ }^{2}$ Program Studi Manajemen, Universitas Tarumanagara Jakarta \\ Email:tigerclops@gmail.com \\ ${ }^{3}$ Program Studi Teknik Industri, Universitas Tarumanagara Jakarta \\ Email:laurenciavanessa@gmail.com \\ ${ }^{4}$ Program Studi Manajemen, Universitas Tarumanagara Jakarta \\ Email:Raymond.yosafat1712@gmail.com
}

\begin{abstract}
Leadership is the main factor that determines whether an organization achieves the goals that have been set, through a number of ways or a distinctive style that is able to influence the activity process of a group. Without leadership an organization consists of just a bunch of confused people and machines. Leadership style can be considered as a modality in leadership, in the sense of ways that a person likes and uses as a vehicle to carry out his leadership. Each leader has his own unique and distinctive nature, habits, temperament or character, and personality, so that his behavior and style will distinguish him from others. Transformational leadership emphasizes the interaction between superiors and subordinates marked by the influence of the leader to change the behavior of subordinates into someone who feels capable and highly motivated and strives to achieve high and quality work performance. In practice, most transformational leadership styles are more effective in enhancing the culture of subordinates. Related education is given to students of SMK Mutiara Bangsa Tiga, especially OSIS, this is intended so that OSIS can apply a transformational leadership style which can ultimately shape the culture in the OSIS organization to be characterized and increase the productivity of activities in OSIS SMK Mutiara Bangsa Tiga. Counseling related to leadership style and culture education is given in the form of speaker programs, experience sharing, questions and answers on real conditions faced by OSIS and other students and how to identify and solve real problems faced.
\end{abstract}

Keywords: leadership style; transformational; culture

\begin{abstract}
ABSTRAK
Kepemimpinan menjadi faktor primer untuk menentukan apakah suatu organisasi mencapai tujuan/misi yang telah ditentukan, dengan sejumlah cara/gaya yang khas yang dapat mempengaruhi keseluruhan proses kegiatan suatu kelompok atau tim. Tanpa kepemimpinan suatu organisasi hanya terdiri dari sekumpulan orang bingung dan mesinmesin. Gaya kepemimpinan kerap dipandang sebagai modalitas dalam kepemimpinan, yang juga berarti sebagai cara-cara yang disenangi dan dipakai seseorang dalam melaksanakan kepemimpinannya. Masing-masing pemimpin memiliki sifat, kebiasaan/habit, temperamen/watak, maupun pribadi sendiri yang unik dan khas, sehingga pola/tingkah laku maupun gaya akan membedakan seorang pemimpin dengan orang lain. Kepemimpinan transformasional menekankan hubungan timbal balik atasan dengan bawahan yang membuat pengaruh pemimpin dalam melakukan perubahan perilaku bawahannya menjadi seorang yang merasakan kemampuan dan termotivasi tinggi guna mencapai prestasi kerja tinggi serta bermutu. Dalam praktek kebanyakan gaya kepemimpinan trasnformasional lebih efektif dalam meningkatkan budaya bawahan. Edukasi terkait diberikan kepada siswa siswi SMK Mutiara Bangsa Tiga khususnya OSIS, hal ini dimaksudkan agar OSIS dapat menerapkan gaya kepemimpinan transformasional yang akhirnya dapat membentuk budaya dalam organisasi OSIS menjadi berkarakter dan meningkatkan produktivitas kegiatan dalam OSIS SMK Mutiara Bangsa Tiga. Penyuluhan terkait edukasi gaya kepemimpinan dan budaya ini diberikan dalam bentuk program speaker, experience sharing, tanya jawab kondisi nyata yang dihadapi OSIS maupun siswa lain dan bagaimana cara mengidentifikasi serta solusi dari permasalahan nyata yang dihadapi.
\end{abstract}

Kata Kunci: gaya kepemimpinan; transformasional; budaya 


\section{PENDAHULUAN}

Kepemimpinan sebagai faktor utama yang menjadi penentu tercapainya tujuan perusahaan, baik dengan cara atau gaya yang khas/unik yang memiliki kemampuan dalam mempengaruhi proses kegiatan suatu tim/kelompok. "Leadership is the process of encouraging and helping others to work enthusiastically toward an objective" dikemukakan oleh Davis dan Newstrom (1989). Tanpa kepemimpinan sebuah organisasi hanya terdiri dari sekumpulan orang-orang bingung dan mesinmesin. Gaya kepemimpinan dapat dipersepsikan sebagai "modalitas" dalam kepemimpinan, yang juga diartikan sebagai cara yang disukai dan seringkali dipakai oleh seorang pemimpin dalam menjalankan kepemimpinannya.

Gaya kepemimpinan adalah norma perilaku yang dipergunakan oleh seseorang guna mempengaruhi perilaku orang lain maupun sebagai pemegang kunci utama untuk terciptanya lingkungan kerja yang baik (Putu dan I Made, 2020). Selain itu dikatakan pula bahwa gaya kepemimpinan merupakan pola perilaku konsisten yang ditunjukkan dan diketahui pihak/orang lain ketika seseorang mencoba mempengaruhi kegiatan/aktivitas orang lain, misal cara memberi arahan, cara penerapan strategi, dan cara memotivasi seseorang/individu dalam mencapai tujuan yang diinginkan (Burhanudin dan Agus Kurniawan, 2020). Pola perilaku seperti ini pengembangannya dilakukan setiap saat dan dipelajari oleh pihak lain guna pengenalan ataupun untuk menilai kepemimpinan seseorang. Meski demikian, gaya kepemimpinan seseorang bukanlah bersifat fixed/tetap, yaitu ketika seorang pemimpin mampu membaca situasi yang dihadapi kemudian menyesuaikan gaya kepemimpinannya dengan situasi tersebut, maka meski penyesuaian itu kemungkinan hanya bersifat sementara. Di sisi lain, setiap pemimpin memiliki sifat, kebiasaan/habit, temperamen atau watak, serta kepribadian sendiri yang unik, maka tingkah laku dan gaya seseorang tersebut yang dapat membedakannya dari orang lain.

Menurut Davis \& Newstrom (1989) dan Widayati et al. (2017), seorang pemimpin turut menentukan Budaya (satisfaction) dan motivasi para karyawannya. Hal ini dimulai dari bagaimana seorang pemimpin menyediakan bantuan (assistance) kepada para karyawan dalam mencapai tujuan. Budaya kerja yang tinggi memberi kontribusi terhadap tujuan organisasi dan pekerjaan, memperbaiki kesehatan fisik - mental serta meningkatnya kualitas hidup di dalam atau di luar pekerjaan. Ketidakpuasan kerja menyebabkan tingginya angka ketidak hadiran, turn over, masalah dalam pekerjaan, keluhan kerja, goncangan terhadap kesatuan kerja organisasi dan menyebabkan iklim organisasi yang negatif. Maka dalam proses kepemimpinannya seorang pemimpin menentukan bagaimana karyawan maupun organisasi mencapai tujuannya.

Bass (1985), kepemimpinan transaksional muncul ketika pemimpin dan bawahan sepakat mengenai hal apa yang harus dilakukan bahwa untuk mendapatkan reward atau menghindari punishment. Kepemimpinan ini menekankan proses transaksi antara atasan dan karyawan, sedangkan kepemimpinan transformasional menekankan hubungan yang saling, antara atasan dan pegawainya yang ditandai dengan pengaruh seorang pemimpin dalam mengubah perilaku bawahan menjadi seorang yang memiliki kemampuan dan termotivasi tinggi serta berusaha terus guna mencapai prestasi kerja setinggi-tingginya dan memiliki mutu yang terbaik. Pengelolaan kepemimpinan perlu ditunjang dengan pembinaan intensif, terencana, maupun terukur bagi semua bawahan (Prahesti et al., 2017). Walaupun kedua gaya kepemimpinan dari Bass (1985), yaitu gaya kepemimpinan transaksional atau gaya kepemimpinan transformasional keduanya berusaha untuk menumbuhkan motivasi bawahan untuk bekerja, tetapi penerimaan bawahan terhadap kedua gaya tersebut belum tentu memuaskan.

Banyak penelitian yang menunjukkan bahwasannya gaya kepemimpinan transformasional memiliki keefektifan dalam meningkatkan Budaya bawahan dibanding gaya kepemimpinan gaya transaksional (Hatter dan Bass, 1988). 
Dalam melakukan fungsinya seorang pemimpin mempunyai gaya tersendiri. Davis dan Newstrom (1989) mendefinisikan gaya kepemimpinan (leadership style) sebagai "total pattern of a leader's actions, as perceived by the leader's employees". Tipe gaya kepemimpinan seorang leader berbeda-beda. Namun tidak ada tipe gaya kepemimpinan yang dapat terbaik ataupun terburuk, karena hal ini sangat tergantung pada kondisi kerja yang dihadapi.

Kegiatan manusia yang dilakukan bersama-sama selalu butuh kepemimpinan. Berbagai usaha dan kegiatan dibutuhkan pula upaya yang terencana, sistematika pelatihan maupun persiapan seorang pemimpin baru. Maka dari itu, studi-studi maupun penelitian dilakukan guna mempelajari masalah/persoalan pemimpin dan kepemimpinan, yang menjadikan teori-teori tentang kepemimpinan bermunculan. Studi-studi kepemimpinan umumnya dapat diklasifikasikan menurut fokus utama yang meliputi: faktor trait pemimpin, perilaku (behavioural approach), situasi (situational approach), dan kepemimpinan Transformasional yang dipandang sebagai suatu subyek yang popular di tahun 1990. Pendekatan kepemimpinan transaksional dan transformasional dari Bass (1985) menggabungkan antara teori trait, behavior, dan situational.

Kepemimpinan transformasional merupakan suatu model kepemimpinan terbaru yang mulai banyak menarik minat para ahli. Model ini menggabungkan unsur-unsur kekuasaan, trait dan tingkah laku. Kata transformasional berasal dari "to transform " berarti mengubah. Konsep kepemimpinan transformasional dalam sejarah kemunculannya tahun 1978 ketika buku "Leadership" James Mc Gregor Burns diterbitkan. Buku ini secara ringkas menjelaskan pola dasar hubungan/interaksi yang dibangun antara atasan dan bawahan, yakni transaksional dan transformasional (dalam Conger dan Kanungo, 1989).

Paradigma kepemimpinan transaksional-transformasional memandang kepemimpinan sebagai masalah contigent reinforcement terhadap para pengikut oleh pemimpin transaksional, atau mengerahkan para pengikut untuk melebihi minat pribadinya semata untuk kebaikan kelompok, organisasi/masyarakat yang dilakukan pemimpin transformasional (Bass, 1997).

Berdasarkan pendapat Hughes, Ginnett dan Curphy (dalam Daryanto dan Daryanto, 2001) seorang pemimpin transaksional berusaha mempertahankan status quo dalam organisasi sedangkan kepemimpinan transaksional berdasar pada otoritas birokrasi serta legitimasi dalam organisasi yang menekankan seorang pemimpin memerlukan penentuan terhadap apa yang dilakukan bawahan guna mencapai tujuan organisasi. Selain itu pula, seorang pemimpin cenderung fokus pada penyelesaian tugas atau permasalahan organisasi.

Pemimpin transaksional akan menjelaskan peran ketika memberikan pengenalan serta penjelasan perihal peranan maupun tuntutan tugas yang diperlukan. Dengan demikian, harapan akan tercapai hasil yang diinginkan serta seorang pemimpin mampu mengenai kebutuhan dan keinginan pegawai. Melalui proses ini terjadilah transaksi antara pemimpin dan bawahan.

Kepemimpinan transaksional berkaitan dengan pertukaran sehari-hari (exchange daily) antara pemimpin dan bawahan, hal ini penting guna mencapai hasil kerja yang sifatnya rutin dan mencapai kesepakatan bersama pada kedua belah pihak. Kepemimpinan transaksional muncul ketika pemimpin dan bawahan berusaha untuk mendapatkan reward atau menghindari punishment. Jika bawahan bertindak atas persetujuan yang telah dibuat, maka pemimpin akan mengatur imbalannya atau aversive reinforcement (misalnya koreksi, hukuman, atau menarik kembali otoritasnya), jika pengikut tersebut melanggar (Bass, 1985). Transaksi semacam ini dapat memberi keyakinan pada bawahan guna menunjukkan usaha/kerja maksimal untuk tercapainya tujuan tertentu. Hal ini dapat terwujud bila sebelumnya pemimpin telah memberikan kejelasan tugas (Yulk, 1989).

Teori kepemimpinan transformasional yang dikembangkan oleh James Mc Gregor Burns (dalam Bass, 1985) dalam penelitian deskriptif tentang banyak pemimpin politik. Dengan mengembangkan model Burns, Bass (1985) merancang teori yang lebih mendetail tentang proses transformasional perusahaan/organisasi dan membandingkan kepemimpinan transformasional, 
kharismatik, dan kepemimpinan transaksional. Perubahan dari kepemimpinan juga saat seorang pemimpin menyampaikan adanya pertimbangan dan suntikan keilmuan dengan individu yang memiliki kharisma. (Robbins dan Judge dalam Dyah dan Mursidi, 2021).

Berangkat dari konsep Burns tentang transaksional, Bass (1985) mengembangkan teori yang lebih detail mengenai proses transformasional dalam organisasi. Pemimpin transformasional menentang status quo dan mengajak pengikutnya untuk bertindak lebih dari yang diharapkan. Bass (1985) menggambarkan kepemimpinan transformasional sebagai pemimpin yang konsentrasi terhadap usaha mencapai tujuan jangka panjang dengan penempatan nilai serta penekanan pada pengembangan visi, melaksanakan perubahan ataupun meluruskan sistem yang disesuaikan dengan visi, daripada bekerja sesuai dengan prinsip-sistem yang sudah ada, serta pelatihan agar bawahan mempunyai tanggungjawab yang lebih dalam pengembangan diri sendiri maupun orang lain.

Dalam kepemimpinan transformasional terdapat lima aspek kepemimpinan, aspek tersebut meliputi attribute charisma, intellectual stimulation, individual consideration, inspirational motivation dan idealized influence. Di dalam pengukuran kepemimpinan transaksional dan tranformasional Bass memasukkan aspek usaha ekstra ke dalam penelitiannya. Usaha ekstra menunjukkan pemimpin yang berusaha keras membangkitkan semangat pegawai/bawahan dalam melakukan berbagai aktivitas yang dirasa sulit. Aktif mendorong, menumbuhkan, mempunyai inisiatif dan mempunyai kinerja yang memadai untuk menjalankan tugasnya.

1. Attribute charisma. Pemimpin mempengaruhi bawahan dengan membangkitkan emosi serta identifikasi dengan pemimpin. Dengan adanya visi, menumbuhkan kebanggaan, rasa hormat serta kepercayaan yang dapat pula meningkatkan optimism pegawai pada diri mereka serta kebersamaan tujuan.

2. Intellectual stimulation. Pemimpin menumbuhkan kreatifitas pegawai dengan cara menanyakan asumsi, penyusunan ulang pertanyaan dan pendekatan yang dipergunakan pada situasi dengan cara yang baru. Ide baru dan solusi kreatif atas suatu masalah berusaha dimunculkan melalui pengikutnya. Pemimpin menyemangati bawahannya untuk mencoba pendekatan baru, dan ide yang dikeluarkan oleh bawahan tidak akan dikritik oleh pemimpinnya.

3. Individualized consideration. Pemimpin menggangap setiap pegawai memiliki pribadi unik/khas, yang cakap, namun dengan kebutuhan maupun keinginan yang berbeda satu dengan yang lain. Memperlakukan karyawan sebagai pribadi yang utuh, berusaha untuk memberikan nasehat yang bermakna, menerima pandangan mendengarkan keluhan bawahan serta memberikan pelatihan yang diperlukan.

4. Inspirational motivation. Atasan mampu menerjemahkan visi yang penuh kepercayaan diri. Atasan menunjukkan keteguhan serta komitmen dalam pencapaian tujuan dan mempunyai wawasan/pandangan luas. Gaya ini membesarkan optimisme juga mampu membangkitkan motivasi bawahannya. Inspirasi pada bawahan dapat dicapai. Hal ini mengakibatkan perasaan bawahan menjadi memiliki kemampuan dalam melaksanakan pekerjaan dan dapat mengemukakan gagasn, menginspirasi, serta membangkitkan kegairahan pegawai untuk memanfaatkan kesempatan meski dalam kondisi yang mengancam dan untuk penyelesaian tugas yang berisiko tinggi dengan hasil memuaskan.

5. Idealized influence. Pemimpin berusaha mempengaruhi bawahan dengan berkomunikasi langsung dan menekankan pentingnya nilai moral, komitmen serta keyakinan pada nilai-nilai memiliki keinginan kuat untuk meraih tujuan dengan mempertimbangkan akibat moral maupun etika pada keputusan yang diambil. Pemimpin menunjukkan kepercayaan akan citacita keyakinan maupun nilai-nilai hidupnya. 
Terkait dengan budaya kerja (job satisfaction), diartikan secara berbeda-beda oleh para ahli. Gibson, Ivancevich, dan Donelly (1989) menyatakan"Job satisfaction is an attitude that individuals have about their jobs ". Robbins (1996) mendefinisikan Budaya kerja sebagai "the difference between the amount of reward workers receive and the amount they believe they should receive". Secara umum Budaya kerja dapat diartikan sebagai persepsi (pandangan) karyawan tentang pekerjaannya yang dinyatakan dalam sikap ataupun tingkah laku. Aspek yang termasuk dalam "pekerjaan" antara lain adalah gaji, kondisi kerja, pengawasan, rekan kerja, keamanan dan lain sebagainya.

Berdasarkan wawancara yang telah dilakukan sebelum kegiatan pengabdian dilakukan, penulis memperoleh gambaran secara lebih dekat tentang keadaan dan program kerja yang sedang dicanangkan oleh ketua OSIS SMK Mutiara Bangsa Tiga. Siswa yang tergabung dalam OSIS, merupakan siswa yang sebelumnya sudah memiliki pengalaman sewaktu SMP dan ada pula yang belum pernah memiliki pengalaman sebelumnya. Namun dalam hal ini, siswa memiliki keyakinan bersama dalam mewujudkan program kerja yang dibuat oleh ketua OSIS dan mendukung kegiatan tersebut. Kepala Sekolah juga memiliki keyakinan yang sama dan akan selalu memberikan dukungan dan bimbingan kepada OSIS dalam menjalankan semua program kerja yang sudah dibuat.

Pada program kerja ketua OSIS terlihat semangat untuk menciptakan solidaritas dan kekompakan antar siswa, semangat untuk berkompetisi secara sportif, dan bertujuan untuk mempopulerkan Mutiara Bangsa Tiga secara bersama-sama.

Dalam hal ini terkait dengan OSIS SMK Mutiara Bangsa Tiga, dari penjelasan di atas tentang gaya kepemimpinan transformasional yang sengaja dipilih, yang menurut anggapan penulis sebagai pendekatan yang paling ideal bagi OSIS saat ini. Kondisi pandemi yang menyebabkan siswa belum dapat hadir di sekolah namun pendidikan tidak boleh berhenti, pengaruh teknologi sedemikian besar, sehingga peluang siswa SMK yang tergabung dalam OSIS dapat pula memanfaatkan teknologi guna kelancaran kegiatan lembaga OSIS sekolah. Upaya diberikan sebagai latihan dan mengajak siswa untuk mengubah pola berpikir dalam menanggapi situasi dan keterbatasan yang terjadi. Dengan memahami gaya kepemimpinan yang ada, siswa dapat mengadopsi hal positif dari gaya kepemimpinan transformasional guna membentuk budaya kerja lembaga OSIS sekolah menjadi lebih baik lagi.

\section{METODE PELAKSANAAN PKM}

Tim PKM Untar yang terdiri dari Herlina Budiono, Steven, Vanessa Angelica Budiono, dan Yosafat Raymond melakukan koordinasi bersama untuk mewujudkan kegiatan pengabdian kepada masyarakat. Kegiatan PKM dengan mitra SMK Mutiara Bangsa Tiga ini bekerja sama dengan Kepala Sekolah SMK Mutiara Bangsa Tiga, Bapak Dani Ramdani. Manfaat yang dapat diperoleh bagi peserta siswa maupun yang tergabung dalam lembaga OSIS antara lain, siswa mendapat pengetahuan dan memahami tipe gaya kepemimpinan transformasional, siswa sebagai generasi $\mathrm{Z}$ dapat menyadari bagaimana gaya kepemimpinan yang ideal yang diharapkan masing-masing siswa. Kegiatan PKM ini dibagi dalam 4 bagian utama pelaksanaan, yaitu: materi yang disusun, proposal awal yang dibuat, pelaksanaan, dan pelaporan akhir. Materi disusun berdasarkan diskusi awal, wawancara pengalaman ketua OSIS kemudian pencarian literatur pendukung mengenai gaya kepemimpinan bagi Gen $\mathrm{Z}$ di masa pandemi sehingga materi terbentuk, padat dan menarik untuk disampaikan kepada peserta. Pelaksanaan berlangsung setengah hari saja sesuai permintaan sekolah yaitu mulai pukul 09.00 sampai dengan pukul 12.00 atau waktu yang disetujui pihak sekolah untuk kebutuhan pelaksanaan, dimana acara akan berlangsung sesuai tahapan mulai dari penyampaian materi, games/permainan, Q\&A dan sharing. 


\section{HASIL DAN PEMBAHASAN}

Dalam Merdeka Belajar Kampus Merdeka (MBKM), Untar sebagai salah satu universitas swasta terkemuka yang unggul selalu berusaha mengedepankan metode belajar yang dapat membuat mahasiswa dan dosen untuk praktek dan menerapkan ilmu yang sudah dimiliki untuk dibagikan ke sekolah-sekolah. Program pengabdian masyarakat Untar pun tidak kalah dalam mengadopsi MBKM, kegiatan PKM melibatkan mahasiswa ini memberikan kemudahan bagi ketua tim PKM baik dalam berkoordinasi maupun pembagian tugas. Pengalaman belajar mahasiswa maupun siswa yang terlibat dalam hal ini siswa-siswi SMK Mutiara Bangsa Tiga maupun lembaga OSIS, diharapkan kemudian dapat berkembang atas kompetensi masing-masing, mampu memahami dan menerapkan gaya kepemimpinan transformasional kearah terciptanya budaya kerja yang baik, efektif, dan efisien dalam kehidupan riil sehari-hari.

\section{KESIMPULAN DAN SARAN}

Kebutuhan akan pengetahuan dan soft skill terkait kepemimpinan telah disampaikan dengan baik. Secara keseluruhan, ketua OSIS mewakili seluruh siswa memperoleh masukan berharga dan terbantu sekali dalam proses bagaimana mengatur dan dinamika dalam kelompok/tim pelaksana program kerja. Proses berpikir dan pemecahan masalah yang mungkin muncul dalam kepemimpinan dibahas dan di-sharing-kan bersama dan memperoleh banyak tanggapan positif. Dalam penyuluhan edukasi di SMK Mutiara Bangsa Tiga, harapan dari pihak sekolah agar penyuluhan seperti yang dilakukan dapat rutin dilakukan. Tim PKM Untar memang sudah beberapa kali mengadakan PKM dengan target siswa-siswi SMK Mutiara Bangsa Tiga. Kesinambungan pelaksanaan membuat siswa memperoleh masukan ilmu pengetahuan, skill tambahan, selain yang sudah dipersiapkan oleh sekolah. Tim PKM yang lain juga diharapkan dapat memberikan penyuluhan lainnya dengan menghubungi pihak sekolah. Kepala sekolah SMK Mutiara Bangsa Tiga sangat terbuka menerima dan menyambut kehadiran tim PKM lain yang berminat untuk hadir.

\section{Ucapan Terima Kasih (Acknowledgement)}

Acknowledgement ini diberikan kepada Bapak Dani Ramdani, S.Pd. selaku kepala sekolah SMK Mutiara Bangsa Tiga dan kepada LPPM yang telah senantiasa memberikan dukungan tanpa henti kepada kami dalam mewujudkan kegiatan pengabdian kepada masyarakat, serta adik-adik mahasiswa yang memberikan kontribusi dalam pelaksanaan PKM.

\section{REFERENSI}

Bass, B.M. (1985). Leadership and Performance Beyond Expectations. New York. The Free Press. (1997). Does the Transactional -Transformasional Leadership Paradigm Trancend Organizational and National Boundaries? American Psycology, 2(2),130-139.

Burhanudin, Agus Kurniawan. (2020). Gaya Kepemimpinan Transaksional dan Transformasional Terhadap Kinerja Kayryawan Bank BRI Purworejo. Jurnal Ilmiah Manajemen. Vol XI No. 1. E-ISSN 2615-4978. P-ISSN 2086-4620.

Conger, Jay A. and Kanungo, Rabindra N. (1989). Charismatic leadership: The elusive factor in organizational effectiveness (First Edition). San Francisco, California: Jossey-Bass Inc.

Daryanto, Arief, dan Daryanto, Heni (2001). Model kepemimpinan agribisnis di masa Depan.

Davis. K, and Newstrom, J.W. (1989). Organization behavior: Human behavior of work. (8 ed.) Singapura Mc Graw Hill. Inc.

Dyah Agustin Widhi Yanti, Mursidi. (2021). Pengaruh Kepemimpinan Transformasional dan Kompetensi Terhadap Kinerja Karyawan. Jurnal Manajemen Strategi dan Aplikasi Bisnis. Vol 4 No. 1 (2021). Pp. 23-34. https://ejournal.imperiuminstitute.org/index.php/JMSAB. 
Gibson, J.L., Ivancevich, and Donelly, J.H. (1989). Organisasi: Perilaku-struktur proses (ed- 2). Jakarta Erlangga.

Hater, J.J., and Bass, B.M. (1988) Superior's Evaluations and Subordinates Perception of Transformational and Transactional Leadership. Journal of Applied Psychology,73(4),695702.

Prahesti, Devi Shinta, I Gede Riana, I Made Arha Wibawa. (2017). Pengaruh Kepemimpinan Transformasional Terhadap Kinerja Karyawan dengan OCB Sebagai Variabel Mediasi. EJurnal Ekonomi dan Bisnis Universitas Udayana 6.7 (2017): 2761-2788. ISSN: 2337-3067.

Putu, Gede Denny Herlambang, I Made Adi Suwandana. (2020). Pengaruh Kepemimpinan Transformasional Terhadap Kinerja Karyawan dengan Self-Efficacy Sebagai Variabel Mediasi pada Lembaga Perkreditan Desa (LPD) di Kecamatan Denpasar Timur. International Journal of Social Science and Business. Volume 4, Number 1, Tahun 2020. Pp. 129-135. P-ISSN: 2614-6533. E-ISSN: 2549-6409.

Robbins, S. P. (1996) Organizational behavior; Concept-controversies-applications (7th ed). Englewood Cliffs, New Jersey: Prentice-Hall.

Widayati Catur, Rahardjo Thea H., Melly Febriyanti. (2017). Pengaruh Gaya Kepemimpinan Transformasional, Motivasi dan Kompensasi Terhadap Kinerja Karyawan. Jurnal Ekonomi. Vol. XXII No.3. November 2017:466-485. Universitas Tarumanagara.

Yulk, G.A. (1989) Leadership in organization ( $2^{\text {nd }}$ ed). Englewood Cliffs, New Jersey: Prentice Hall. 
Seminar Nasional Hasil Penelitian dan Pengabdian Kepada Masyarakat 2021

Pengembangan Ekonomi Bangsa Melalui Inovasi Digital Hasil Penelitian dan

Pengabdian Kepada Masyarakat

Jakarta, 21 Oktober 2021

(halaman kosong) 